Brazilian Journal

of Chemical

ISSN 0104-6632

Engineering

\title{
DECOLORIZATION AND REMOVAL OF COD AND BOD FROM RAW AND BIOTREATED TEXTILE DYE BATH EFFLUENT THROUGH ADVANCED OXIDATION PROCESSES (AOPS)
}

\author{
A. Muhammad*, A. Shafeeq, M. A. Butt, Z. H. Rizvi, M. A. Chughtai and S. Rehman \\ Institute of Chemical Engineering \& Technology, University of the Punjab, \\ Phone: +( 92) 42923126, Fax: +(92) 429231159, Lahore (54590), Pakistan. \\ E-mail: atozmoon@yahoo.com
}

(Received: October 3, 2006 ; Accepted: March 10, 2008)

\begin{abstract}
In this paper, a comparative study of the treatment of raw and biotreated (upflow anaerobic sludge blanket, UASB) textile dye bath effluent using advanced oxidation processes (AOPs) is presented. The AOPs applied on raw and biotreated textile dye bath effluent, after characterization in terms of COD, colour, BOD and $\mathrm{pH}$, were ozone, $\mathrm{UV}, \mathrm{UV} / \mathrm{H}_{2} \mathrm{O}_{2}$ and photo-Fenton. The decolorization of raw dye bath effluent was $58 \%$ in the case of ozonation. However it was $98 \%$ in the case of biotreated dye bath effluent when exposed to $\mathrm{UV} / \mathrm{H}_{2} \mathrm{O}_{2}$. It is, therefore, suggested that a combination of biotreatment and AOPs be adopted to decolorize dye bath effluent in order to make the process more viable and effective. Biodegradability was also improved by applying AOPs after biotreatment of dye bath effluent.

Keywords: Biodegradation; Dyes; Ozonation; Pollutant; AOPs.
\end{abstract}

\section{INTRODUCTION}

The textile, paper, food processing and tanning industries have experienced significant economic development during the past two decades, accompanied by extremely high consumption of water. The textile industry produces large quantities of highly colored effluents, which are generally toxic and resistant to destruction by biological treatment methods. Most of the dyes used are of complex structured polymers. Particularly reactive azo dyes cause special environmental concern due to their degradation products, such as aromatic amines which are highly carcinogenic (APHA, AWWA and WEF Standard Methods for the Examination of Water and Wastewater, 1995; Arslan and Seremet, 2004). The use of a variety of dyes and auxiliary chemicals results in the discharge of toxic waste into natural water bodies. These industries are thus facing problems in maintaining a profitable level of production while reducing the intake of fresh water. Another problem is the disposal of large volumes of effluents which abides by environmental standards. These are generally not amenable to conventional biological, physical and chemical treatment processes due to their recalcitrant and complex nature (Arslan et al., 1999; Azbar et al., 2004).

Advanced oxidation is a potential alternate method to decolorize and reduce recalcitrant wastewater loads from textile dyeing and finishing effluents (Balcioglu and Arslan, 1999). Chemical oxidation using ultraviolet radiation (UV) in the presence of hydrogen peroxide $\left(\mathrm{H}_{2} \mathrm{O}_{2}\right)$ is a very promising technique. The most common technique is the use of UV wavelengths (200-300) nm at $254 \mathrm{~nm}$ to disassociate $\mathrm{H}_{2} \mathrm{O}_{2}$ progressively. The $\mathrm{UV} / \mathrm{H}_{2} \mathrm{O}_{2}$ systems generate hydroxyl radicals $(\mathrm{OH} \bullet)$, which are highly powerful oxidizing species. Hydroxyl radicals can oxidize organic compounds (RH) producing organic radicals $(\mathrm{R} \bullet)$, which are highly reactive and

*To whom correspondence should be addressed 
can be further oxidized (Baxendale et al., 1957; Bolton et al., 1996; Camel and Bermond, 1998; Catalkaya et al., 2003). Almost 700,000 tons of approximately 10,000 types of dyes and pigments are produced annually worldwide, of which about $20 \%$ are assumed to be discharged as industrial effluent during the textile dyeing processes. Aerobic biological degradation is not always effective for the purpose of color removal from textile dyecontaminated effluent. Since biodegradation products can be of a toxic nature, success with treatment by biodegradation can be limited and specifically the treatment of synthetic dyestuff cannot depend on biodegradation. Up to $50 \%$ for reactive dyes, $8-20 \%$ for disperse dyes and 1\% for pigments may be lost directly into effluent, resulting in a colored effluent, due to the inefficient dyeing process and the nature of the dyes, which after hydrolyzation do not react with the fiber (Azbar et al., 2004). Commonly applied treatment methods for color removal from dye contaminated effluents consist of integrated processes involving various combinations of biological, physical and chemical decolorization methods. Advanced oxidation processes $\left(\mathrm{O}_{3}, \mathrm{O}_{3} / \mathrm{H}_{2} \mathrm{O}_{2}, \mathrm{O}_{3} / \mathrm{UV}, \mathrm{UV} / \mathrm{H}_{2} \mathrm{O}_{2}\right.$, $\mathrm{O}_{3} / \mathrm{UV} / \mathrm{H}_{2} \mathrm{O}_{2}$ and $\mathrm{Fe}^{2+} / \mathrm{H}_{2} \mathrm{O}_{2}$ ) for the degradation of nonbiodegradable organic contaminants in industrial effluents are attractive alternatives to conventional treatment methods. AOPs based on the generation of very reactive and oxidizing free radicals have been used with increasing interest due to their high oxidant power. Also many studies have demonstrated that AOPs are effectively removing color and partially removing the organic content of dyestuffs (Chen et al., 1997; Galindo et al., 2001; Glaze et al., 1987; Gulyas et al., 1995; Thobanoglous et al., 2003).

\section{EXPERIMENTAL SETUP FOR ADVANCED OXIDATION PROCESSES}

Advanced oxidation of raw and biotreated (UASB) textile dye bath effluent (Real, obtained from local textile industry) was carried out by applying ozonation, $\mathrm{UV}, \mathrm{UV} / \mathrm{H}_{2} \mathrm{O}_{2}$ and photo-Fenton processes at ambient temperature and pressure. The upflow anaerobic sludge blanket (UASB) uses an anaerobic process while forming a blanket of granular sludge suspended in the tank. Wastewater flows upwards through the blanket and is processed by the anaerobic microorganisms. All the experiments were carried out for the effluent sample of $0.5 \mathrm{~L}$ in batch mode at a constant $\mathrm{pH}$ of 6.2 and adjusted by adding $1 \mathrm{~N} \mathrm{NaOH}$ to raise the $\mathrm{pH}$ to 10.2 or $1 \mathrm{~N} \mathrm{HCl}$ to lower the $\mathrm{pH}$ to 3.5 upon decolorization. The highest decolorization rate was observed at $\mathrm{pH} 6.2$ without adjustment with $\mathrm{NaOH}$ or $\mathrm{HCl}$ and was selected for the decolorization condition of dye bath effluent in all the experiments. One of the major factors which may affect the efficiency of color and COD removal is $\mathrm{pH}$, particularly in the cases of the ozonation and photoFenton processes (Sigge et al., 2002). A bubble column type reactor consisting of a graduated Pyrex glass vessel (internal diameter $5 \mathrm{~cm}$ and height 30 $\mathrm{cm}$ ) and a magnetic stirrer was utilized.

\section{Ozonation Process}

A JQ-6M PURETECH model ozone generator with the capacity to produce ozone at a concentration of $5 \%$ was employed. High purity oxygen at a concentration of $99.5 \%$ was introduced at a rate of $3.5 \mathrm{l} / \mathrm{min}$. into the ozone generator. However, the real doses of ozone applied into the reactor through a fine bubbling stone, were estimated at $1.5 \mathrm{1} / \mathrm{min}$. of oxygen. Ozonation time was varied from (5 to 30 ) min. for both raw and biotreated effluent. Ozonetreated effluent was sampled at regular time intervals for determination of COD and color removal efficiencies.

\section{UV Photo-Reactor}

A UV lamp model PENRAY 3SC9 (Upland, USA) with a radiation intensity of $5 \mathrm{~mW} / \mathrm{cm}^{2}$ and wavelength of $254 \mathrm{~nm}$ was positioned within the center of reactor. As the most biologically disruptive frequencies are the shortest wavelengths within ultraviolet (UV) light, known as the UV-C spectrum ranging from (200 to 300$) \mathrm{nm}$, the UV emission spectrum at $254 \mathrm{~nm}$ was utilized.

\section{Hydrogen Peroxide Setup}

The hydrogen peroxide $\left(\mathrm{H}_{2} \mathrm{O}_{2}\right)$ used in this study was of analytical grade (35\%) and was obtained from Merck (Germany). The dosage of $\mathrm{H}_{2} \mathrm{O}_{2}$ used for all the tests performed was first optimized at a constant $\mathrm{pH}$ of 6.2 for the samples in each study by varying the dosage from $(50-200) \mathrm{mg} / \mathrm{l}$. The optimized dose of $\mathrm{H}_{2} \mathrm{O}_{2}$ above which the decolorization effect was weakened was found to be in the range of (150-200) $\mathrm{mg} / \mathrm{l}$ for raw and (100-150) $\mathrm{mg} / \mathrm{l}$ for biotreated effluent.

\section{Analytical Methods}

Textile dye bath effluent was characterized in terms of color, COD, BOD and $\mathrm{pH}$ at ambient temperature in accordance with APHA, AWWA and WEF Standard Methods for the Examination of Water and Wastewater, 1995. The dye bath effluent was characterized for an absorption spectrum of (200-600) $\mathrm{nm}$ and was found to be highest at $465 \mathrm{~nm}$. 
Table 1: Characterization of Raw and Biotreated Textile Dye Bath Effluent

\begin{tabular}{|l|c|c|}
\hline Parameter & Raw & Biotreated \\
\hline COD (mg/l) & 750 & 154 \\
A* (Color) & 1.8 & 1.2 \\
BOD (mg/l) & 261 & 76.2 \\
pH (units) & 12.1 & 8.4 \\
\hline
\end{tabular}

*Absorbance of color at $465 \mathrm{~nm}$

\section{ADVANCED OXIDATION OF RAW TEXTILE EFFLUENT}

\section{Ozonation}

In this study the effect of ozonation time on removal of COD, color and BOD was investigated with oxygen at a purity of $99.5 \%$ fed into the ozone generator. The removal of COD, color and BOD initially increased with ozonation exposure time up to $25 \mathrm{~min}$. and did not change appreciably thereafter. This can probably be explained by the fact that some organic compounds are more susceptible to oxidation than others, while some are only partially oxidized (Camel and Bermond, 1998). Although, Ozone itself is a highly oxidizing agent, even then various $\mathrm{pH}$ values have a large effect on COD removal, which increases at higher $\mathrm{pH}$ values (Azbar et al., 2004). The results shown in Figure 1 imply that dye bath effluent can be decolorized efficiently at a constant $\mathrm{pH}$ of 6.2 by ozonation, i.e., $58 \%$ at a $25 \mathrm{~min}$. exposure time.

\section{Irradiation}

Raw textile effluent was exposed to UV irradiation alone and the removal of COD, color and BOD was found to be highest at a $25 \mathrm{~min}$. exposure time, i.e., $28 \%, 26 \%$ and $34 \%$, respectively, as shown in Figure 2 , and seemed to decrease thereafter. Percentage removal was not appreciable due to the fact that the UV supported process is generally applied to the aqueous wastes of low color intensity, while in this study the textile effluent color was of high intensity. This high color intensity might have prevented the uniform penetration of UV light throughout the sample

\section{$\mathrm{UV} / \mathrm{H}_{2} \mathrm{O}_{2}$}

It is obvious from Figure 3 that $35 \%, 32 \%$ and $44 \%$ of COD, color and BOD, respectively, were removed. Percentage removal was not appreciable, due to the fact that hydroxyl radical production in the presence of UV may require a specific $\mathrm{pH}$. However, a decolorization efficiency may be enhanced by applying $\mathrm{UV} / \mathrm{H}_{2} \mathrm{O}_{2} / \mathrm{O}_{3}$ or increasing the concentration of $\mathrm{H}_{2} \mathrm{O}_{2}$ to ensure the availability of hydroxyl radicals.

\section{Photo-Fenton Process}

Figure 4 illustrates that the best results for the removal of color, $\mathrm{COD}$ and $\mathrm{BOD}$ were obtained at a $25 \mathrm{~min}$. exposure time to UV irradiation, 40\%, 38\% and $68 \%$ respectively and after 25 min., removal remained constant.

\section{Comparison of AOPs}

It is obvious from Figure 5 that decolorization and COD and BOD removal are higher in case of ozonation of raw textile dye bath effluent than with all other AOPs applied, with the exception that percentage removal of BOD was found to be highest in the case of exposure to photo-Fenton. Thus ozone was shown to be effective as a strong oxidizing agent, specially with respect to $\mathrm{COD}$ and color removal. As $\mathrm{UV} / \mathrm{H}_{2} \mathrm{O}_{2}$ requires acidic conditions for reasonable removal efficiency (Shu and Chang, 2005), its probable failure to be the most effective in our study may have been due to the $\mathrm{pH}$ used, i.e., 6.4. However, in the presence of UV or $\mathrm{H}_{2} \mathrm{O}_{2}$, along with ozone, the decolorization rate could be enhanced. 


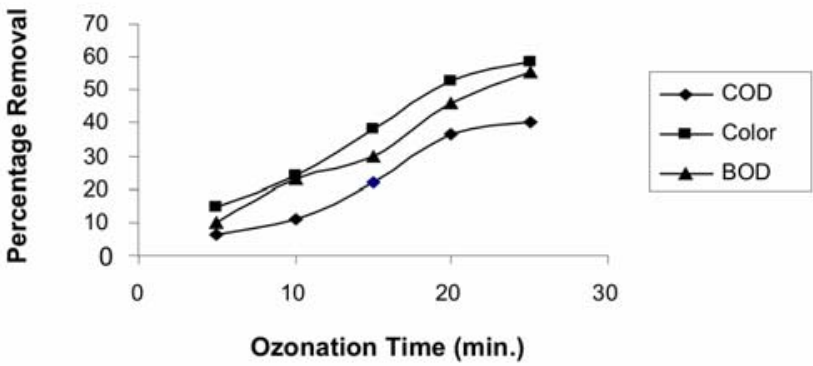

Figure 1: Effect of ozone-liquid contact time on COD, color and BOD removal

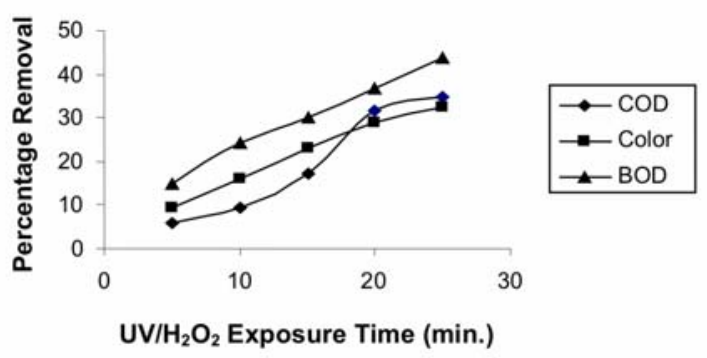

Figure 3: Effect of $\mathrm{UV} / \mathrm{H}_{2} \mathrm{O}_{2}$-liquid contact time on $\mathrm{COD}$, color and $\mathrm{BOD}$ removal

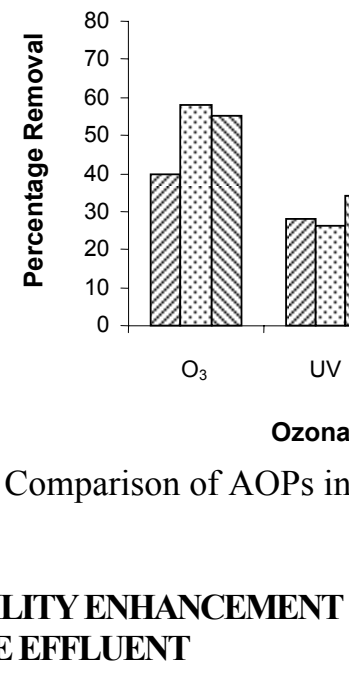

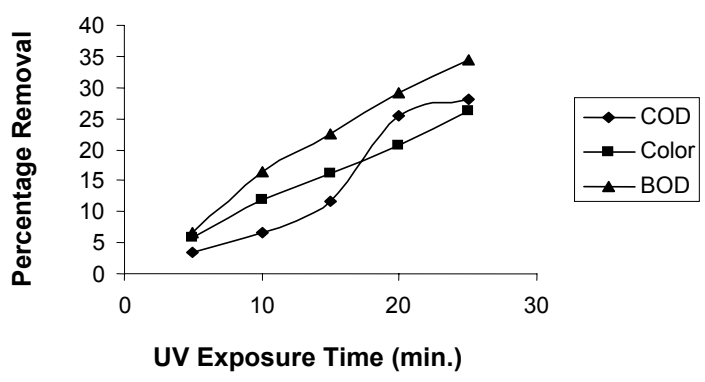

Figure 2: Effect of UV-liquid contact time on the $\mathrm{COD}$, color and BOD removal

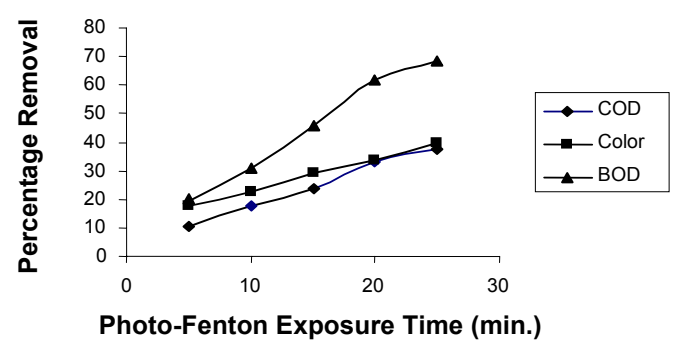

Figure 4: Effect of photo-Fenton-liquid contact time on $\mathrm{COD}$, color and BOD removal

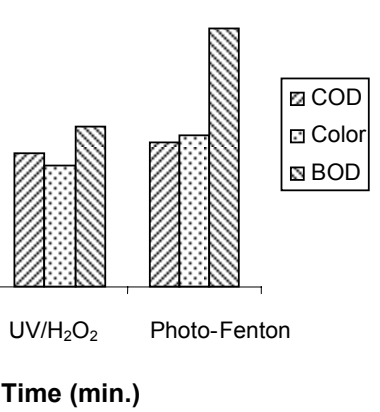

Figure 5: Comparison of AOPs in terms of COD, color and BOD removal

The improvement in biodegradability in all the experiments was followed by measuring the change in $\mathrm{BOD} / \mathrm{COD}$ ratio. Adoption of the two-step sequence, i.e., biological treatment along with oxidation of effluents, is thus suggested to obtain the greatest advantage with application of AOPs. The goal of advanced oxidation processes is not to mineralize the compounds (i.e., convert to $\mathrm{CO}_{2}$ and $\mathrm{H}_{2} \mathrm{O}$ ), but rather to convert biorecalcitrant compounds into intermediates which are readily biodegradable in conventional biological treatment processes. Biodegradability of the raw textile

\section{STUDY OF BIODEGRADABILITY ENHANCEMENT OF RAW TEXTILE EFFLUENT}

Brazilian Journal of Chemical Engineering effluents showed a sudden improvement from 0.35 to $>1$ up to an exposure time of $15 \mathrm{~min}$., which could be due to high BOD and then continuously decreased with the increase in exposure time in all the oxidation processes, as shown in Figure 6. This may be due to the fact that initially all AOPs were able to destroy recalcitrant components of the effluent or that no appreciable amount of recalcitrant material was present in the initial stages. Mineralization of organic matter into $\mathrm{CO}_{2}$ and water takes place in highly oxidative environments, yet its existence cannot be ignored here either. The effect of $\mathrm{H}_{2} \mathrm{O}_{2}$ concentration on BOD and COD measurements is of considerable importance, but was not considered in all the processes employed in the current work. 


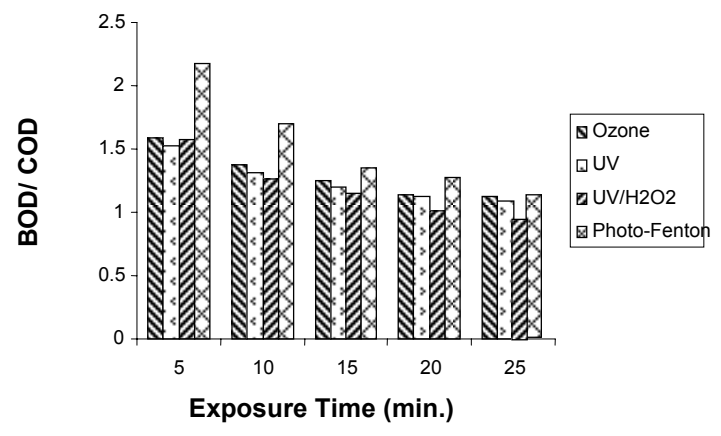

Figure 6: Biodegradability improvement of raw textile effluent

\section{ADVANCED OXIDATION OF BIOTREATED (UASB) TEXTILE EFFLUENT}

A 2.5L laboratory-scale up flow anaerobic sludge blanket (UASB) bioreactor was used and operated at $35^{\circ} \mathrm{C}$. The volume of the biogas was determined using a barometric unit equipped with an electronically controlled counter and a gas-tight valve and the volumes were adjusted to standard temperature and pressure. The substrate was fed semicontinuously into the bioreactor by means of a peristaltic pump (Watson-Marlow 302S) controlled by an electronic timer. The bioreactor was run at a hydraulic retention time (HRT) of 36 h. The bioreactor effluent was characterized in terms of COD, color, $\mathrm{BOD}$ and $\mathrm{pH}$, as shown in Table 1.

\section{Ozonation}

The ozonation experiments of UASB-treated effluent were performed at a constant $\mathrm{pH}$ of 6.2 and ozone ( $5 \%$ conc.) dosage at a pure oxygen supply of $1.5 \mathrm{1} / \mathrm{min}$. with quite promising results (Figure 7), i.e., percentage removal values of $75 \%$ COD, $95 \%$ color and $85 \%$ BOD at a $25 \mathrm{~min}$. exposure time. The degree of color removal initially increased with dose of ozone administered, but showed no appreciable decolorization thereafter, which may be due to the fact that biotreatment had already lowered the intensity of the dye bath effluent.

\section{UV Irradiation}

Decolorization and COD removal by applying UV irradiation were $79 \%$ and $80 \%$, respectively, as shown in Figure 8. Decolorization was quite appreciable because the color of UASB-treated effluent was already less intense. However, the color removal efficiency was further improved due to uniform distribution of UV light throughout the sample.

\section{$\mathbf{U V} / \mathrm{H}_{2} \mathbf{O}_{2}$}

It is clear from Figure 9 that the increase in color and COD reduction with time is not linear, i.e., it is initially rapid up to a $20 \mathrm{~min}$. exposure time and then decreases with time, which indicates that UASB-treated effluents may contain considerable amounts of compounds that require a stronger oxidizing system.

\section{Photo-Fenton Process}

The photo-Fenton process is an important emerging technology in the field of oxidation processes. All the tests were performed using concentration of $\mathrm{FeSO}_{4}(10 \mathrm{mg} / \mathrm{l})$ for $30 \mathrm{~min}$. of UV exposure time. Disruption of the biological substances occurred mostly between UV spectrum of (200-300) nm, so the used wavelength is considered to be appropriate for this process. In Figure 10 it can be observed that percentage removal after a $25 \mathrm{~min}$. exposure time was $61 \%, 86 \%$ and $69 \%$ COD, color and BOD, respectively; thereafter no appreciable removal efficiency was observed

\section{Comparison of AOPs}

Decolorization of biotreated textile dye bath effluent was most efficient, and reached up to $95 \%$ in the cases of both ozone and $\mathrm{UV} / \mathrm{H}_{2} \mathrm{O}_{2}$. COD removal in all AOPs was found to occur in the following descending order $\mathrm{UV} / \mathrm{H}_{2} \mathrm{O}_{2}, \mathrm{UV}, \mathrm{O}_{3}$ and photoFenton. Thus, in Figure 11, it can be observed that $\mathrm{UV} / \mathrm{H}_{2} \mathrm{O}_{2}$ was the most efficient in terms of both $\mathrm{COD}$ and color removal. It can also be presumed that the simultaneous application of $\mathrm{UV}$ and $\mathrm{H}_{2} \mathrm{O}_{2}$ to biotreated effluent is a promising AOP technique for potential industrial implementation. 


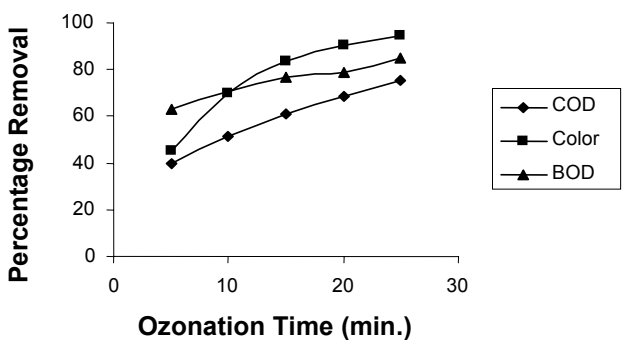

Figure 7: Effect of Ozone -liquid contact time on $\mathrm{COD}$, color and BOD removal

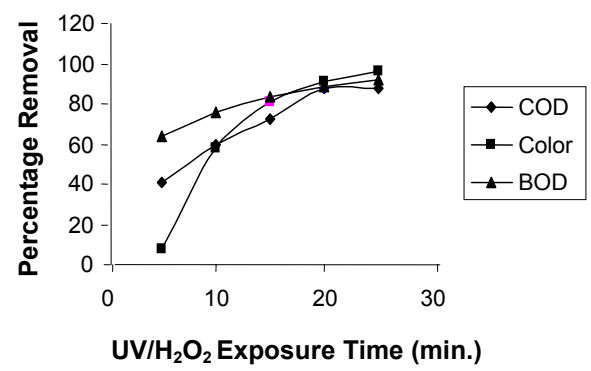

Figure 9: Effect of $U V / \mathrm{H}_{2} \mathrm{O}_{2}$-liquid contact time on COD, color and BOD removal

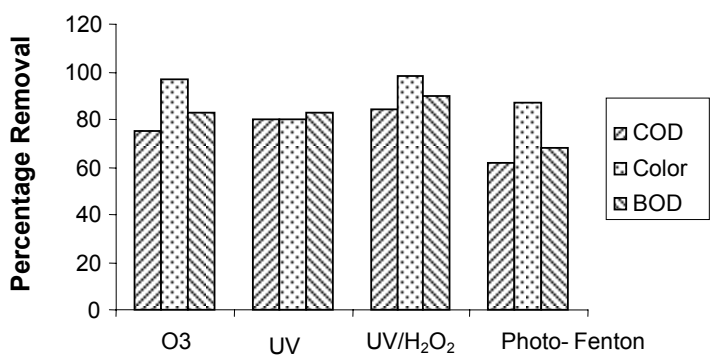

Exposure Time (min.)

Figure 11: Comparison of AOPs in terms of percentage removal of COD, color and BOD.

\section{BIODEGRADABILITY IMPROVEMENT OF TREATED TEXTILE EFFLUENT}

The biodegradability of the biotreated textile effluents also initially increased suddenly from 0.5 to $>1$ and then decreased continuously during application of all the AOPs, which is obvious in Figure 12, as the biodegradable components had already been removed during biotreatment and only biorecalcitrant matter was left in the effluent to either be converted in to biodegradable matter or turned in to highly recalcitrant or inert matter.

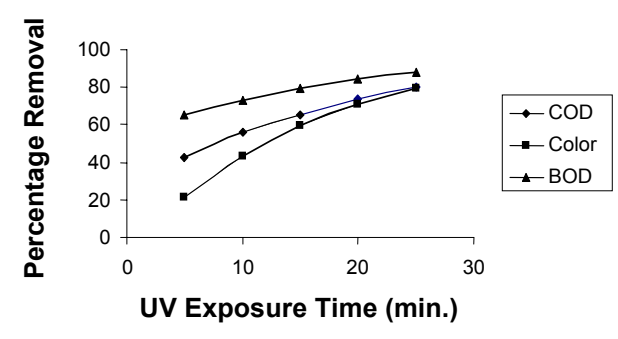

Figure 8: Effect of UV-liquid contact time on COD, color and BOD removal

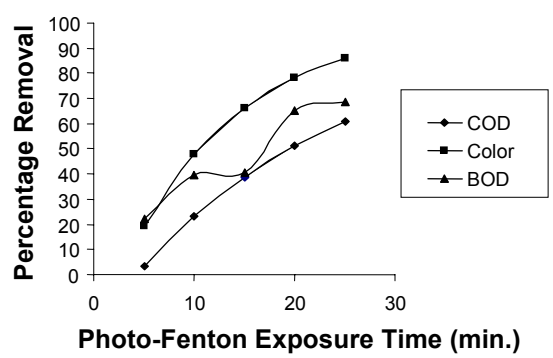

Figure 10: Effect of photo-Fenton-liquid contact time on the removal of COD, BOD and color

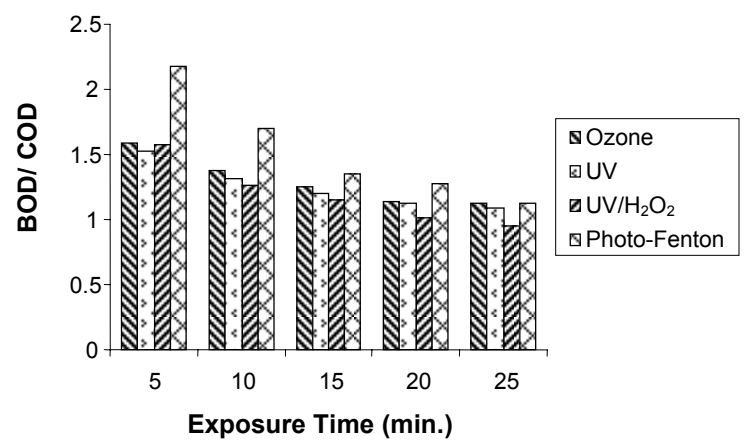

Figure 12: Biodegradability improvement of biotreated textile effluent

\section{CONCLUSIONS}

In the past AOPs had been thoroughly and comparatively evaluated for a variety of organic compounds in wastewaters as well as dye bath effluents, but with several limitations (Azbar et al., 2004). Decolorization of textile effluents is a major environmental concern and problems of feasibility and cost effectiveness remain to be solved. The application of a combined method, i.e., biotreatment (UASB) and AOPs for treating dye bath effluent, is advantageous. This combined approach not only 
allows better achievement of decolorization efficiency, but also contributes towards reducing treatment costs. Thus application of AOPs to biotreated textile effluent is more effective than their use with raw effluent. Ozonation of raw textile effluent is probably better for decolorization than the AOPs applied. However, in the case of biotreated textile effluent, the efficiency of decolorization was higher with UV/H2O2 than with the other AOPs applied.

\section{REFERENCES}

APHA, AWWA and WPCF, Standard Methods for the Examination of Water and Wastewater, 19th ed., American Public Health Association, Washington, D.C., 1995.

Arslan, I. and Seremet, O., Advanced Treatment of Biotreated Textile Industry Wastewater with Ozone, Virgin/Ozonated Granular Activated Carbon and Their Combination, Toxic/Hazardous Substances \& Environmental Engineering, 39(7): 1687-1700 (2004).

Arslan, I., Balcioglu, I. A. and Tuhkanen, T., Advanced Oxidation of Synthetic Dyehouse Effluent by $\mathrm{O}_{3}$, $\mathrm{H}_{2} \mathrm{O}_{2} / \mathrm{O}_{3}$ and $\mathrm{H}_{2} \mathrm{O}_{2} / \mathrm{UV}$ Processes, Env. Tech., 20: 921-931 (1999).

Azbar, N., Yonar, T. and Kestioglu, K., Comparison of Various Advanced Oxidation Processes and Chemical Treatment Methods for COD and Color Removal from a Polyester and Acetate Fiber Dyeing Effluent, Chemosphere, 55: 35-43 (2004).

Balcioglu, I. and Arslan, I., Treatment of Textile Industry Wastewater by Enhanced Photo Catalytic Oxidation Reaction, J. Adv. Oxid. Tech., 4 (2): 189-195 (1999).

Baxendale, J. H. and Wilson, J. S., The Photolysis of Hydrogen Peroxide at High Light Intensities, Trans. Faraday Soc., 53: 344-356 (1957).

Bolton, J. R., Bircher, K. G., Tumas, C. A. and Tolman, C. A., Figures of Merit for the Technical
Development and Application of Advanced Oxidation Processes, J. Adv. Oxid. Tech., 1 (1): 13-17 (1996).

Camel, V. and Bermond, A., The Use of Ozone and Associated Oxidation Processes in Drinking Water Treatment, Water Research, 32, 3208-3222 (1998).

Catalkaya, E., Bali, U. and Sengul, F., Photochemical Degradation and Mineralization of 4chlorophenol, Env. Sci. Pollut. Res., 10 (2): 113118 (2003).

Chen, J., Rulkens, W. H. and Bruning, H., Photochemical Elimination of Phenols and COD in Industrial Wastewaters, Wat. Sci. Tech., 35 (4): 231-238 (1997).

Galindo, C., Jacques, P. and Kalt, A., Photochemical and Photocatalytic Degradation of an Indigoid Dye: a Case Study of Acid Blue 74 (AB74), J. Photochem. Photobiol. A., 141 (1): 47-56 (2001).

Glaze, W. H., Kang, J. W. and Chapin, D. H., The Chemistry of Water Treatment Processes Involving Ozone, Hydrogen Peroxide and Ultraviolet Radiation, Ozone Sci. Eng., 9: 335352 (1987).

Gulyas, H., Von Bismarck, R. and Hemmerling, L., Treatment of Industrial Wastewaters with Ozone/Hydrogen Peroxide, Wat. Sci. Tech., 32(7): 127-134 (1995).

Shu, H. Y. and Chang, M. C., Pre-Ozonation Coupled with $\mathrm{UV} / \mathrm{H}_{2} \mathrm{O}_{2}$ Process for the Decolorization and Mineralization of Cotton Dyeing Effluent and Synthesized C.I. Direct Black 22 wastewater, J. of Hazardous Materials B121, 127-133 (2005).

Sigge G. O., Britz T. J., Fourie P. C., Barnardt, C. A. and Strydom R., Combining UASB Technology and Advanced Oxidation Processes (AOPs) to Treat Food Processing Wastewaters, Water Sci. Tech., vol. 45, no. 10, pp. 329-334 (2002).

Thobanoglous G., Burton F. L. and Stensel H. D., Wastewater Engineering Treatment and Reuse, McGraw Hill Companies Inc. (2003). 